\title{
Imperative Markers: A Comparison of Monolingual and Bilingual Early Language Acquisition
}

Arathi Raghunathan, Gayathri Krishnan and Vaijayanthi M. Sarma

'Bare' verbs are in abundance in early acquisition data. The presence of these verbs is one of the reasons for hypothesizing the lack of agreement inflections or projections in early language acquisition theories. The affirmative, singular, imperative form is the only 'bare' form in the adult grammar and we argue that child grammar is no different (Lakshmanan, 2006). The bare forms in the data are not really bare. It provides clues to how the grammar is organized internally and how the typologies of the languages that a child is exposed to might influence early utterances.

Imperatives are produced as an order, command or request. Usually, these productions in children are accompanied by gestures or a peak in intonation (Sarma, 1999). Cross-linguistically, imperatives are morphologically sparse (Schwager, 2011). The subject of an imperative is optional even in languages that require them ordinarily, for example, English. In this paper, we focus on the morphological marking of the imperative mood and not the periphrastic imperative structures. Drawing on evidence from longitudinal monolingual and bilingual first language acquisition data, we will argue that typological differences play out differently in monolingual and bilingual inflectional development taking Malayalam and English imperatives as cases in point. We shall attempt to explain the occurrence of certain imperative forms in the language context by tracing the differences and similarities in the spontaneous acquisition data of two monolingual children and one bilingual child.

\section{Contextualizing Imperatives in the Two Languages}

Typological differences between different inflectional systems (e.g. agglutinative vs. fusional systems, prefixing, suffixing or infixing systems etc.) are also important in determining the success of morphological segmentation that is performed by children. It has been proposed that a child born in a language setting with rich inflectional morphology (where more dimensions are marked and more distinctions drawn within a single dimension) will be more attuned to morphological features than a child born in a language setting with sparser inflectional morphology, where fewer such distinctions are drawn. This might explain the observation that the sparse verbal-agreement morphology of English is acquired relatively late when compared to the acquisition of rich inflectional systems. Furthermore, the inflections in agglutinative systems are observed to be acquired comparatively earlier than in fusional systems. This is because agglutinative systems have less semantic complexity (since there is a one-to-one correspondence between the inflectional marker and its grammatical dimension), and greater morphological transparency compared to other systems where affixes express a combination of feature specifications, and trigger modifications of the stem to which they are attached. The most revealing evidence regarding the influence of typological systems comes from the studies on 
bilingual children acquiring typologically different inflectional systems. Studies on Basque-Spanish bilingual children have shown that Basque not only is acquired first, but also delays the acquisition of Spanish (Penke, n.d.). However, in this paper we will demonstrate that it is not the typological advantage that is the determining factor in Malayalam-English bilingual acquisition, but the dominant language at that particular phase in the inflectional development, taking imperative-marking as the case in point.

English is an Indo-European language with an SVO word order. It is a head-initial language that requires mandatory subjects. Unlike other Indo-European languages like Italian or Spanish that make use of inflections, English verbs make use of periphrastic elements to express grammatical relationships. The verb forms mark tense morphologically in the simple present and past tenses. The future is expressed periphrastically using modal verbs as in (2). Verbal agreement inflection is observed in the present-tense, for the third-person singular subject, which is written as /-s/ 'plods' in most cases; the past tense morpheme is written as /-ed/ 'plodded' for all regular verbs in English; and the progressive form is written as /-ing/ 'plodding' for all English verbs. All other tense/aspects verb forms are periphrastic as shown in the following examples (1-3).

(1) He had taken the book (Perfect aspect)

(2) He will go. (Modal verb)

(3) I was going. (Progressive aspect)

This makes English an analytic language, that makes use of supporting words to convey grammatical relationships. In English, imperatives are bare, emphatic, or negative as in the following examples (4-6). The latter two are periphrastic.

(4) Go there (bare).

(5) Do come home! (emphatic or request)

(6) Do not enter! (do-support, negative)

Malayalam is a Dravidian language, with an SOV word order. It is a head-final language that allows topic-drop. In Malayalam, an agglutinative language with a rich inflectional system, verbs typically inflect for tense, aspect, and mood, and do not agree with their subjects. Past, present and future tenses are morphologically marked in Malayalam, unlike English where only the past and present are marked. The following suffixes are added to the verbal root to bring out tense distinctions in finite verbs: past 'tu' as in kaqi-ccu 'ate'; present 'unnu' as in kaøiykk-unnu 'eats'; future 'um' as in kayiykk-um 'will eat'. Malayalam marks the imperative mood in a variety of ways. In addition to the bare form of the verb as in (5), inflections such as -oo, -ee, -aan signal increasing degrees of emphasis, examples (7-10) and -anta is used to indicate the negative imperative as in (11). Additionally, forms, as in (12) are honorific and are used to signal respect which are not typically found in children's speech.

(7) poo "go" (bare-Mal)

(8) pokk-oo [go-IMP-V]

(9) pokk-ee [go-IMP-V]

As appeared in the proceedings of the 40th International Conference of the Linguistic Society of India, Trends in Applied Linguistics and Language in Use, ed. Tariq Khan, 2020 
(10) pook-aan [go-IMP-V],

(11) pook-anta [go-NEG IMP] (negative)

(12) pook-uu, pook-uvin [go-IMP-HON-V]

In early child language, the imperative forms take the second person, nominative. Overt subjects are optional in these second person imperative forms. When they are marked, it is either parenthetical or to create an emphasis. The imperative verb permits complements including embedded non-finite, sentential complements. In fact, imperatives may themselves be selected as finite complements by other matrix verbs. In the following example, the imperative is selected by the matrix verb /parayuka/ 'to say' and itself selects an infinitival TP (a quotative verb).

\section{(13) [laksmi [ CPP $_{T P} \quad$ keeral-attileeykki torri-ni poykk-oo] ennit] miiraj-ootí para-nnu] Lakshmi.NOM Kerala-LOC tour-DAT go-IMP that.COMP Meera-SOC say-PAST 'Lakshmi told Meera, “(You) Go to Kerala for the tour”.}

As pointed out in Sarma (1999), there are three identifiable differences between imperative structures and the nominative-accusative finite clauses in Tamil. These are shared by Malayalam as well. The context of utterance is crucial to understand the imperative. (i) the absence of an overt subject NP in Spec, TP, (b) the subject is most frequently assumed to be second person unless overtly specified otherwise and (c) tense is not specified overtly.

Affirmative and negative imperatives in English are formed in the same manner, using the same set of morphological endings on the verb stem. English being an analytic language, is inflectionally deficient. Leszek (1995) notes that the imperative mood is identical to the present indicative in English (examples 14 and 15 (a) \& (b)). However, the majority of English imperatives are understood to be second person singular or plural commands. Present indicative verbs in third person singular can be distinguished by their inflection as in 15(c).

(14) Imperative: (You) run [2SG-NOM run-IMP-V]

(15) Present Indicative: (a) I run [1SG-NOM run-V]

(b) You run [2SG-NOM run-V]

(c) He runs [3SG-NOM run-PRES-V]

Leszek (1995) also notes that according to Stockwell, Schacter and Partee (1973), there are certain imperative constructions in English such as the let imperatives, imperatives with overt subjects, and imperatives containing the verb 'to be' that do not seem to fit the paradigm and so are not considered "true imperatives".

Our aim in this paper is to compare the occurrences of imperative inflectional markers in two different linguistic environments: (i) monolingual Malayalam acquisition and (ii) simultaneous acquisition of Malayalam and English. We believe that the tokens of imperatives within these two contexts provide a context which enables us to understand not only the cross-linguistic differences in inflectional acquisition, but also how the interplay of two different 
linguistic systems (analytic vs agglutinative in this context) affects the inflectional production in bilingual acquisition. One of the crucial points to be noted in language acquisition research that involves bilingualism is the dominance of one linguistic system over the other. The language system within each participant is dynamic and is influenced by the domain of use (Grosjean, 2004). In order to understand the same, we analyze our bilingual data using the mean length of utterance (MLU).

\section{Subjects and Methodology for data collection}

We look at the longitudinal acquisition data of two monolingual Malayalam-acquiring children, a girl and a boy, and one English-Malayalam acquiring bilingual girl child. The monolingual girl child whom we label A, was recorded between the ages of 1;9.14 and 2;10.3, and the monolingual boy child, whom we label $\mathrm{H}$, was recorded between the ages of 2;3.28 and $3 ; 0.17$. Overall, A was recorded over 26 sessions and $\mathrm{H}$ over 18 sessions. Both children belong to middle class families for whom Malayalam was the only language of communication at home and in the larger social environment.

The English-Malayalam acquiring bilingual girl child, E, was recorded between the ages of $1 ; 10.7$ and 2;11.3. She was recorded over 30 sessions. The parents are both bilinguals in Malayalam and English, who use both languages to speak to her. Although the language of the local community is Kannada, E is not exposed to it yet. E is exposed to Malayalam and English from birth and therefore qualifies as a candidate for simultaneous bilingualism. $\mathrm{E}$ is clearly separating the two linguistic systems as may be evidenced by the choice of head-direction in her utterances. The following examples from her data elaborates this case in point.

(16) E: al farnd It

I-1SG-NOM find-PST-V it-PRN

'I found it.'

(17) E: bo:l kalccanam

ball-N play-DEB-V

bs:l kaliykkanam

[adult form]

'(We) must play with the ball.'

English is a strong head-initial language and the verb precedes its complement as in example (16) whereas Malayalam is a head-final language and the complement precedes the verb as in (17).

Spontaneous, natural speech samples were collected from A, H and E. Each recording session was about 40 to 60 minutes long. Recordings were done once every fortnight, in the children's homes. The spontaneous speech samples included their interactions, mostly with the researchers, and occasionally with their caregivers (mothers and grandparents). The data used for this paper was transcribed and analyzed in ELAN (Wittenburg et al. (2006)). Imitations, rhymes, 
songs, number listings, non-words, false-starts, fillers and repetitions were excluded from the analysis.

\section{Imperative Marking in the Data}

We first examine E's Mean Length of Utterance (MLU), which is the number of morphemes per utterance, to understand language dominance in her linguistic development. On observing Figure 1 , it can be seen that the Malayalam MLU values of the bilingual child E is comparatively less than that of the two monolingual children $\mathrm{A}$ and $\mathrm{H}$. This is not particularly surprising since she has fewer number of inflections compared to the monolingual children. Figure 1. suggests that $\mathrm{E}$ is slightly dominant in English. She prefers to speak in English more often than in Malayalam and has 2579 utterances in English and 1504 utterances in Malayalam.

Fig 1. A's, E's and H's MLUs

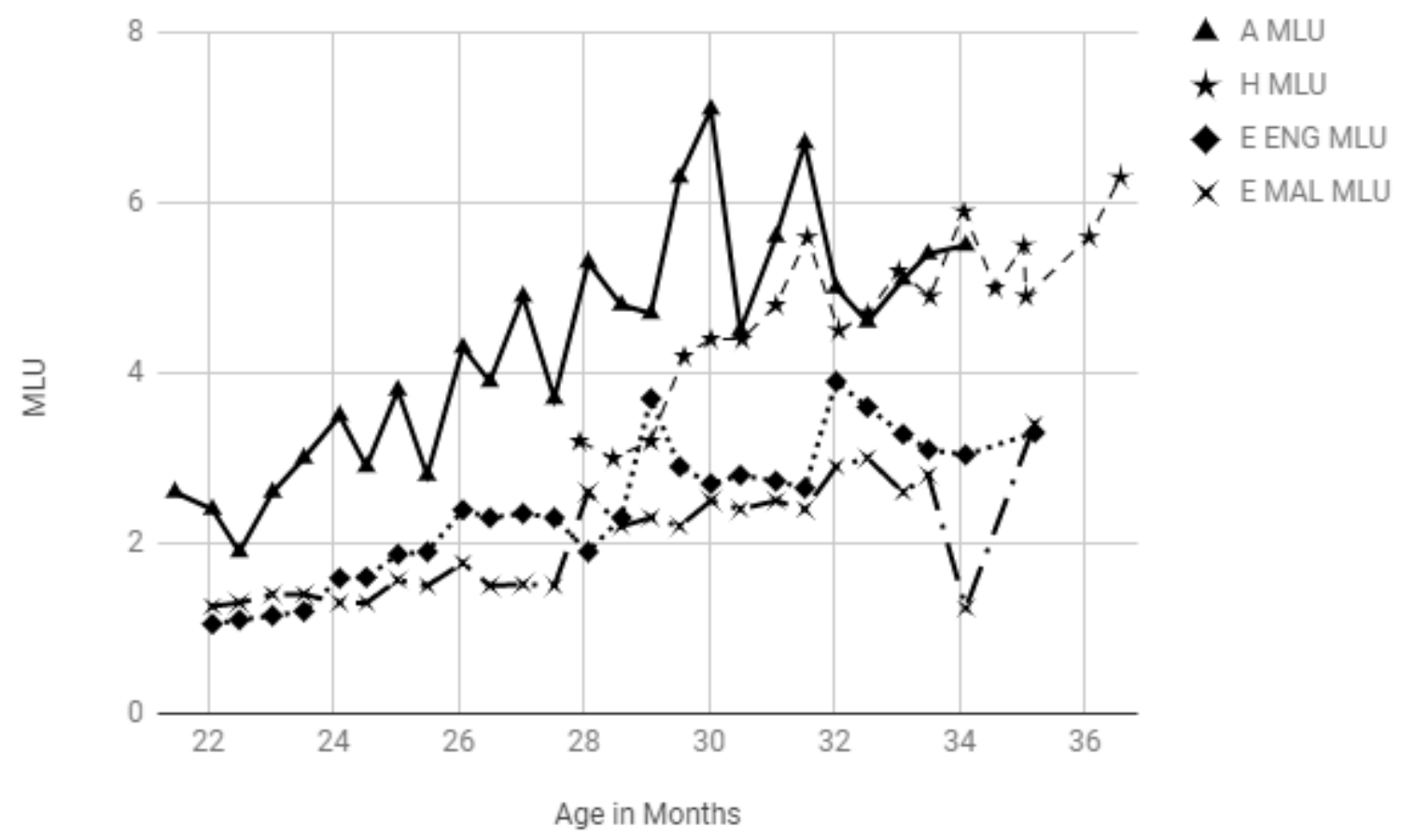


Table 1. General Inflections and Imperative tokens in the data Imperative Tokens

\begin{tabular}{llllll} 
Malayalam & \multicolumn{3}{c}{ inflectional } & Total \\
subject & bare forms & - aan & $-e e$ & - oo & \\
A & 99 & 38 & 52 & 30 & $99: 120$ \\
H & 81 & - & 28 & 13 & $81: 41$ \\
E & 350 & 0 & 53 & 8 & $350: 61$ \\
English & affirmative & & & Total \\
subject & bare forms & & & \\
E & 1547 & & & 1547 \\
\hline
\end{tabular}

Table 1. elaborates the tokens of imperatives in the speech samples, classified according to imperative inflections. A's imperative productions comprise the productive use of all the major imperative markers as expected of a child learning Malayalam.

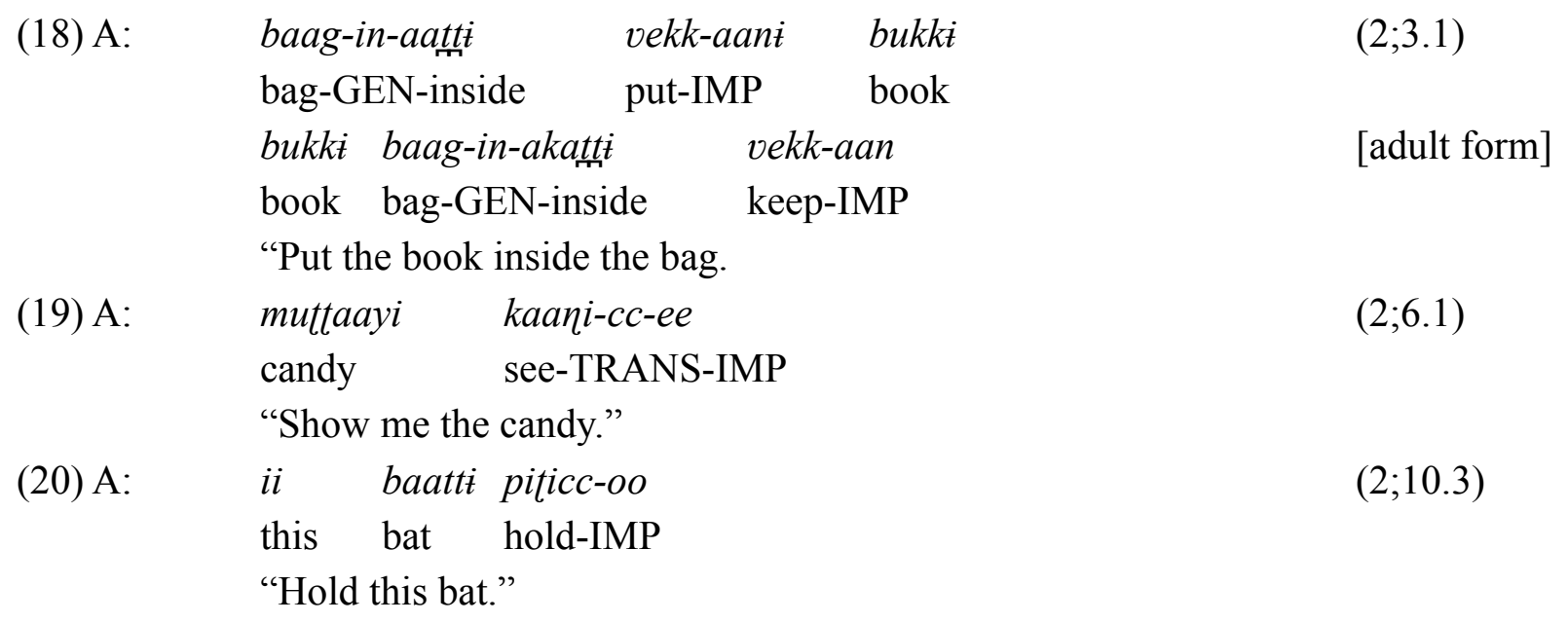

$\mathrm{H}$ has both -ee and -oo in place but does not mark any verb with the most emphatic imperative morpheme-aan. 
(21) $\mathrm{H}$ :

$\begin{array}{ll}a-c c-\dot{t} & \text { itt-ee } \\ \text { close-TRANS-PP } & \text { put-IMP }\end{array}$

ata-cc-i itt-ee

close-TRANS-PP put-IMP

[adult form]

"Keep the door closed."

(22) $\mathrm{H}$ :

$\begin{array}{ll}\text { kucc-oo } & \text { amm-ee } \\ \text { drink-IMP } & \text { mom-VOC }\end{array}$

"Mom, drink."

E, however, makes use of bare forms in most of her imperative productions, both in English and Malayalam as shown in Table 1. The following are examples of bare imperatives from her data.

sli:p sım taim

English, (2;10.5)

sleep.IMP some time

"Sleep (for) some time."

(24) E: $\quad$ lait idit

Malayalam, $(2 ; 4.11)$

light put.IMP

"Put the light."

Like H, E's Malayalam data does not include an instance with the inflection -aan. The other imperative morphemes are found in E's Malayalam data as can be seen below:

(25) $\mathrm{E}$

$\begin{array}{llll}n i: & \text { oru } & \text { baubau } & \text { varacc-ee } \\ \text { you.2SG a-DET } & \text { dog.*0ACC } & \text { draw-IMP }\end{array}$

$(2 ; 11.2)$

ni: oru pattiy-e varacc-ee

[correct form]

"You draw a dog."

(26) E: de: kalcc-oo

here play-IMP

de: kalicc-oo

[adult form]

"Here! Play."

$\mathrm{E}$ at $2 ; 11.2$ is yet to productively use the imperative inflections in Malayalam when compared to $\mathrm{A}$ and $\mathrm{H}$, except for the morpheme -ee, for which her instances are greater in number (53 instances) than the monolingual H's (28 instances) and is on par with A's (52 instances). $\mathrm{A}$ and $\mathrm{H}$ also have a lot of bare imperatives in their speech, but E's bare imperative instances exceed the tokens of the monolingual children by over 251 against A and 269 against H. Examples of Malayalam bare imperatives in the data are given below. 
(27) A

$\begin{array}{lll}\text { amm-ee } & \text { pott-icc- } \dot{t} & \text { taa } \\ \text { mom-VOC } & \text { break-TRANS-PP } & \text { give.IMP }\end{array}$

"Mom, open this for me."

(28) $\mathrm{H}$ :

amm-aa ivite iri
mom-VOC here sit.IMP
"Mom, sit here."

The morpheme -aan is only present in A, indicating an individual preference. The use of morpheme -ee is common for all the children. However, a majority of E's imperative tokens are in English. Children are expected to acquire the inflectional markers in Malayalam, a rich inflectional language, early. While A and $\mathrm{H}$ clearly show facility with the imperative markers, $\mathrm{E}$ does not.

Table 2. Total Inflectional Tokens

\section{Subject Malayalam Inflections English Inflections}

$\begin{array}{lll}\text { A } & 3354 & \text { NA } \\ \text { H } & 1868 & \text { NA } \\ \text { E } & 557 & 532\end{array}$

\section{Discussion}

This paper focused on the occurrence of Malayalam imperatives in monolingual and bilingual contexts. We specifically examined the number of tokens in each context. From the data in Table 1, it can be inferred that Malayalam imperative inflections are considerably less in the bilingual context and that they are high in the Malayalam monolingual context. The tokens of bare imperatives in English are more than four times the number of bare imperatives in E's Malayalam data.

The three main factors that influence the acquisition of any marker are i) formal complexity, ii) relative salience, and iii) productivity (Dressler, 2012). These factors play a crucial role in the child's acquisition of Malayalam inflections. As we mentioned earlier, Malayalam is an agglutinative language with a rich inflectional system. Characteristic of agglutinative languages, Malayalam inflections, including the imperative, are easily segmentable and phonologically salient. They are syllabic, salient, easily segmentable, and productive. In 
addition to the three factors mentioned above such as formal complexity, relative salience and productivity, frequency of occurrence also plays an important role in the acquisition of inflectional morphemes as can be seen from E's data.

According to Hauser-Grüdl et. al. (2010), cross-linguistic patterns reflect "child-internal processes" that help bilingual children to choose the less complex path when confronted with a complex grammatical situation in one language. English is the dominant language in the bilingual context as deduced using the MLU values in Figure 1. Although in comparison with A and H, E's values for MLU are low, her MLU ranges in English are comparable with the MLU ranges of monolingual English children from Brown (1973) as demonstrated in Table 3. Also, Malayalam will have greater MLU values in general since it has more number of morphemes per word than English.

Table 3. Brown's Stages for Monolingual English Acquisition

\begin{tabular}{|c|c|c|c|}
\hline Brown's Stages & Age in Years & MLU Range & E's MLU Range \\
\hline Stage I & $1-2 ; 2$ & $1.0-2.0$ & $1.05-2.39$ \\
\hline Stage II & $2 ; 3-2 ; 5$ & $2.0-2.5$ & $2.35-2.3$ \\
\hline Stage III & $2 ; 6-2 ; 8$ & $2.5-3.0$ & $2.7-3.9$ \\
\hline Stage IV ${ }^{1}$ & $2 ; 9-3 ; 3$ & $3.0-3.75$ & $2.8-3.4$ \\
\hline
\end{tabular}

The inflectional count for both $\mathrm{A}$ and $\mathrm{H}$ are higher than $\mathrm{E}$. Almost all major inflections of the language are acquired by $\mathrm{A}$ and $\mathrm{H}$ during the period of study and these are productively used as well. E does acquire most of the inflections in English and Malayalam but does not seem to use them productively as suggested by the total inflectional count in Table 2 and her lower MLU values for Malayalam compared to the two monolingual children in Figure 1. Most of her imperative tokens are in English. E chooses to speak mostly in English and English is not as richly inflected as Malayalam. Whenever an imperative is required, she seems to prefer speaking in English. She prefers to use bare English imperatives as they are less complex in structure. This is seen to affect the total inflectional count in the data when compared with Malayalam monolingual children. This kind of a preference for English is not only seen in the imperatives, but also while marking the plural where she substitutes the English plural markers instead of the required Malayalam counterparts.

$$
\begin{aligned}
& \text { kamma }{ }^{*} \\
& \text { earring-0PL* }
\end{aligned}
$$

\footnotetext{
${ }^{1}$ E's longitudinal data collection was over before the completion of Stage IV (at the age $2 ; 11$ ). 
kammalu-kal

earring-PL

'Earrings'

(30) E: $\quad$ miin- $z^{*}$

fish-PL*

miinu-kal

fish-PL

'Fishes.' [correct form]

[correct form]

These examples clearly suggest that there is a marked preference for the English system.

Early language learners have limited exposure to their target language. Frequency plays a crucial role in the early phase of language acquisition (Ellis, 2002). The morpheme -ee is the most frequently used imperative inflection by adult Malayalam speakers as it covers several contexts such as suggestion and request, and the more expected commands unlike the other imperative markers. The results obtained after analysing the data suggest a parallel in children. We have provided sample sentences from the data to elaborate the various types of morphological imperative markers in Malayalam in section 3. The inflectional marker -ee is found to be the most frequently employed imperative inflection by all the three children (refer Table 1).

In the bilingual child, we can see that the English system has a direct impact on the production of its imperatives. Although $\mathrm{E}$ is aware of the two languages, it is possible for features from one language to influence the other in early bilingual development (De Houwer, 1990; Döpke, 1998). English imperatives are bare or periphrastic and Malayalam allows bare imperatives. Therefore, using bare imperative forms seems to be a default strategy that $\mathrm{E}$ has adopted. The high occurrence of imperatives in E's data is one such instance of cross-linguistic influence of English over her Malayalam productions. While her Malayalam bare forms surpass both the monolingual children's, the inflectional production can be seen to suffer in general except for the inflected -ee forms. The surfacing of the marker -ee in quite a similar number as in the monolingual children suggests the role frequency can play in overriding the existing dominant system which is English in E's case (as shown by Fig 1.). While she employs the bare forms as the default strategy in Malayalam and English as it is an available structure in both the languages, E employs Malayalam imperative inflections for emphasis as suggested by the following examples from her data.

(31) E: $\quad$ weəz mai pз:s?

where-Q is-PRES my-POSS purse-N

"Where is my purse?"

GF: gəv and pIk It

As appeared in the proceedings of the 40th International Conference of the Linguistic Society of India, Trends in Applied Linguistics and Language in Use, ed. Tariq Khan, 2020 
go-IMP and-CONJ pick-IMP it-PRN

"Go and pick it."

E: appacca pidicc-ee, ammacc-i pidicc-ee

Grandfather.MASC hold-IMP grandmother-FEM hold-IMP

"Hold (it) grandfather, hold (it) grandmother."

(32) E: $\quad i d i$ id baubau alla

this-DET dog-N no-NEG

"This is not (a) dog."

AR: $\quad$ baubau alle? pinneyoo?

dog-N no-NEG-Q then-Q

"Not a dog? Then?"

E: $\quad i d \dot{i} \ldots \quad n i: \quad$ oru baubau varacc-ee

this.DET you.2SG a.DET dog. ${ }^{*} 0 \mathrm{ACC}$ draw-IMP

ni: oru pattiy-e varacc-ee [correct form]

you.2SG a.DET dog-ACC draw-IMP

"You draw a dog."

In (31), E is playing with her grandparents and identifies their bag as her purse. When her grandfather removes the bag from her sight she asks for her 'purse' which she then places at another place. The grandfather asks her to pick the purse up from where she left it. But she insists on her grandparents' picking it up. In (32), E is looking at a picture of an elephant and recognizes that the animal in the picture is not a dog. When the researcher further asks her what that animal is, she suddenly insists the researcher to draw a dog for her.

\section{Conclusion}

The factors that come into play in monolingual acquisition seem to pan out differently in the bilingual acquisition context as suggested by Yip \& Mathew, 2003; Müller \& Hulk, 2001 and Nicoladis, 2002. Because of language dominance, language development in young bilinguals can bring in features from one language to the other as demonstrated in this paper. Bilingualism may be manifested in different ways (De Houwer, 2009). The most frequent imperative context is as an address to a second person. The differences in the imperative data indicate that while the typological advantage is exploited in typical monolingual inflectional development, it is outweighed by the typology and word-formation patterns of the dominant language at a given point in time in bilingual inflectional development, unless high-frequency use allows the bilingual child to override the dominant language's strategy and to instantiate the required inflectional marking when the data are unambiguous. 


\section{References:}

BROWN, ROGER. 1973. A first language: the early stages. Cambridge, Mass.: Harvard. University Press.

DE HOUWER, ANNICK. 1990. The acquisition of two languages from birth: $A$ case study. Cambridge: Cambridge University Press.

DE HOUWER, ANNICK. 2009. Bilingual first language acquisition. Clevedon/Buffalo: Multilingual Matters.

DOPKE, SUSANNE. 1998. Competing language structures: the acquisition of verb placement by bilingual German-English children. Journal of Child Language Volume 25 / Issue 03, pp 555-584.

DRESSLER, WOLFGANG. U. 2012. On the Acquisition of Inflectional Morphology: Introduction. Morphology 22, pp 1-8.

ELAN (Version 5.2) [Computer software]. (2018, April 04). Nijmegen: Max Planck Institute for Psycholinguistics. Online: https://tla.mpi.nl/tools/tla-tools/elan/.

ELLIS, NICK. C. 2002. Frequency effects in language processing: A review with implications for theories of implicit and explicit language acquisition. Studies in Second Language Acquisition 24 (2):143-188.

GROSJEAN, FRANCOIS. 2004. Studying Bilinguals: Methodological and Conceptual Issues. In Tej K. Bhatia and William C. Ritchie (eds.), The Handbook of Bilingualism, pp. 32-64. Australia: Blackwell Publishing.

HAUSER-GRUDL, N., ARENCIBIA GUERRA, L., WITZMANN, F., LERAY, E., \& MULLER, N. 2010. Cross-linguistic influence in bilingual children: Can input frequency account for it? Lingua 120(11), 2638-2650.

LAKSHMANAN, U. 2006. Assessing linguistic competence: Verbal inflection in child tamil. Language Assessment Quarterly 3, pp 171-205.

LESZEK. A. S. 1995. A critical study of imperatives. Online: https://dspace.mit.edu/bitstream/handle/1721.1/11837/32875284-MIT.pdf?sequence=2.

MAGDALENA SCHWAGER. 2011. Imperatives and Tense. In Renate Musan \& Monika Rathert (eds.), Tense Across Languages. Niemeyer. pp. 541-37.

MULLER, N., \& HULK, A. 2001. Crosslinguistic influence in bilingual language acquisition: Italian and French as recipient languages. Language and Cognition 4(1), 1-21.

NICOLADIS, E. 2002. What's the difference between "toilet paper" and "paper toilet"? French-English bilingual children's cross-linguistic transfer in compound nouns. Journal of Child Language 29, 843-863.

PENKE, M. (n.d.). The Acquisition of Inflectional Morphology. (Submitted in The Handbook of Morphology, Wiley-Blackwell) 
SARMA, VAIJAYANTHI. 1999. Case, agreement and word order: issues in the syntax and acquisition of Tamil. Doctoral Dissertation, MIT.

WITTENBURG, P., BRUGMAN, H., RUSSEl, A., KLASMANN, A., SLOETJES, H. 2006. ELAN: a Professional Framework for Multimodality Research. In: Proceedings of LREC 2006, Fifth International Conference on Language Resources and Evaluation. Online: http://www.lrec-conf.org/proceedings/lrec2006/pdf/153 pdf.pdf.

YIP, V. \& S. MATTHEWS. 2000.Syntactic Transfer in a Cantonese-English Bilingual Child. Bilingualism: Language and Cognition 3(3), pp.193-208. 